\title{
DIGITAL TRANSFORMATION IN ART PEDAGOGICAL TRAINING IN VIETNAM TODAY
}

\section{Son Duc Nguyen}

\section{Article History}

Received: 19 October 2020

Accepted: 05 December 2020

Published: 30 December 2020

\section{Keywords}

Digitalize, digital

transformation, art

pedagogical training, higher

education

\author{
Sai Gon University, Vietnam \\ Email:ducson@digitalart.world
}

\section{INTRODUCTION}

Nowadays, the development of information technology in the context of the $4^{\text {th }}$ Industrial Revolution has swiftly transformed education and training and posed various new problems in the field. The explosion of the social networking platforms, mobile devices, big data, cloud computing, etc. is shaping an era of digitalised education. Consequently, many "smart education" models are being developed thanks to the effective application of information technology in the knowledge constructing and developing process in the aim of well-rounded individual development for everyone. Digital transformation has become a growing trend of businesses, organizations, etc. all over the world. Moreover, the process of globalization has given rise to many forms of non-traditional education and sustaining innovations capable of bringing knowledge across space, time, and borders around the world (Marshall McLuhan \& Powers, 1989).

In the context of the industrial revolution 4.0, technology is constantly changing in line with the development trends of the whole society, which forces education and training institutions to constantly update technology trends to avoid the risk of lagging behind in such a competitive "education market". However, this is also a good opportunity for universities to make a successful breakthrough because all the benefits and impacts that technology application brings ultimately aim at improving their training capacity and contributing to sustainable development of Vietnamese education. A series of policies to promote the digital transformation of education have been issued, gradually completing the legal corridor involving regulations on the application of information technology in managing and organizing online training, distance training, educational management, operation and exploitation of the centralized database system throughout the country; guidelines of information technology tasks for training institutions and other state management documents on digital transformation in education and training. Most notably and importantly, the "National Digital Transformation Program up to 2025, with a vision to 2030" approved by the Prime Minister, emphasizes that education is one of the top priorities in digital transformation (Prime Minister, 2020).

In the context of global integration, Vietnam in general and the education and training sector in particular cannot avoid the global trend and must act urgently so as not to miss the opportunity that the 4th Industrial Revolution brings about. Vietnam's education sector has been digitized with an open database from the central government to 63 departments of education and training nationwide, 710 education and training divisions and about 53,000 educational institutions. Currently, the data of about 53,000 schools has been digitized and verified, including more than 300 universities and colleges, 1,4 million teachers, 23 million school pupils and college students (Ngoc Linh, 2020). However, the current situation of information technology application and digital transformation in Vietnam's 
education sector is still below expectation, being at the early development stage and facing plentiful challenges. Further research and development is urgently needed for digital transformation in arts education and training.

The article mentions and analyzes the changes among universities, lecturers in terms of art teaching methods and art pedagogical training in the process of digital transformation in order to propose a digital transformation model to shape and develop digital transformation strategies.

\section{LITERATURE REVIEW}

In the paper "Digital Transformation in Education" (Bilyalova, 2019), the author considered digital technology in the modern world as a tool and also a living environment that opens up new opportunities in the context of digital age: learning at one's convenience, continuing education, etc. This research aims to clarify the situation of digital education, the current state of its implementation and the expected results. Accordingly, this type of education must be critically analyzed in terms of the advantages and risks the learners may encounter as well as and the effectiveness of the teaching - learning process.

Despite various definitions of digital transformation in the existing literature, it can be generalized that Digital Transformation is the process of transforming an organization's activities from the real world to the virtual environment in cyberspace (the Internet). As a result, members within the organization may have access to more information, shorten distances, narrow space, save time and effort, and increase stakeholder satisfaction and experience, helping organizations solve many of its own limitations and create momentum for sustainable development. It can be said that Digital Transformation is an inevitable accelerating trend, especially in the context of the current the Industrial Revolution 4.0.

Based on the general concept of Digital Transformation, in the education sector, it can be understood as the transformation of educational activities from real to virtual (digital) environments. Activities are carried out with the help of technology and engineering. The participation of information technology changes how training institutions approach learners, how they teach or relate to each other, operate and manage training, and deal with organizational challenges in implement their own activities, thereby improving the training quality and efficiency. Digital transformation is not determined by technology, but instead focuses more on the impact of technology on education. Digital conversions can range from simple to systematic, which can be manifest with advanced technologies and completely new models; or the transition may be less, even low-tech, but still transforming results effectively for training institutions

Digital transformation in art and design training has recently been brought into focus of scholars and educators. The doctoral dissertation entitled "Learning During a Digital Transformation in Communication Design: Faculty, Professional, and Student Views on Changing Pedagogical Practices” (Scherling, 2020) showed that digital technologies have become fundamental to communication designers in their professional practices. The speed of technological change has been remarkable, and communication design educators, professionals, and students are challenged with reimagining what constitutes an education responsive to digital transformation. The research attempts to answer the question of how educators can best prepare and support communication design students for what awaits them in the near future workplace.

Moreover, there are several studies on arts teaching methodologies in the context of digital transformation. For example, the research "Teachers' Perceptions of the Digital Transformation of the Classroom through the Use of Tablets: A Study in Spain" (C. Suárez-Guerrero, 2016) examines the transformation of classroom dynamics brought about by the use of tablets for educational purposes. This study shows that teachers viewed tablets not only as a technological challenge, but also as an opportunity to rethink their traditional teaching models.

In the world, many countries have been implementing national strategies for digital transformation such as in the UK, Australia, and Denmark, etc. Digital transformation content is very wide and diverse, but there are certain common key contents, including: digital government (online public services, open data), digital economy (digital finance, e-commerce), digital society (education, health, culture), and digital transformation key industries (agriculture, tourism, electricity, transportation). According to statistics of University World News in 2017, Vietnam ranks among the top 10 in Asia to catch up and develop online training strongly. Also in the same year, data from Ambient Insight showed that the growth rate of online learning in Vietnam ranked the highest, at 44.3\%, $4.9 \%$ higher than that of regional countries such as Malaysia (Ngoc Linh, 2020).

In Vietnam nowadays, the informatics competencies of administrators, lecturers and non-teaching staff in schools are limited and uneven. Elderly lecturers only have limited access to information technology with mostly self-taught 
computer literacy without basic training. Furthermore, their hesitancy and timidity are formidable obstacles in their attempts to effectively innovate and apply information technology in management and teaching practices. Meanwhile, the digital database including e-books, e-libraries, multiple choice question banks, electronic lectures, elearning softwares, and simulation application softwares is still developed spontaneously, lacking sufficient order and systems. It is difficult to control the quality and learning content, which lead to the lack of synchronization and sharing among schools, and eventually a common waste of resources. The exploitation of educational management data and digital data needs a common legal corridor in accordance with the regulations on copyright, intellectual property, information security, electronic transactions, and the law of supply sharing (Politburo, 2019).

Digital transformation in the field of art pedagogy promotes the digitalization of the teaching and learning environment, the library (learning and research resources); increasing application of software solutions to manage, store and preserve digital contents in an expanding worldwide connection; rapid changes in the model of university to digitize art pedagogical training in Vietnam; people's awareness of the impact of architects on all activities of teaching and learning art; developing and applying digital skills in learning and research; creativity in the digital environment; the development of an Internet-linked environment for cross-border education, smart education on digital platforms, etc.

\section{RESEARCH METHODS AND RESULTS}

\subsection{Research methods}

In this article, an interdisciplinary approach between education, arts and design, science, and technology is employed to generalize the theoretical framework and determine the status of digital transformation in arts training and art pedagogical training in Vietnam.

\subsection{Research results}

\subsubsection{The role of technology in the art education digital transformation process}

Digital transformation can help higher education in general develop rapidly and sustainably, while also fostering transforming disciplines that adapt in response to social needs. The benefits of technology to education in general and art pedagogy are undeniable.

Digital transformation enhances teaching efficiency. The essence of digital transformation is strategic thinking for the application of information and communication technologies in teaching and learning processes. Thereby, to meet the requirements of the society and training objectives properly and promptly with optimal expenses and use of time and resources and help higher education to deal with and overcome real-world challenges and create new opportunities. Moreover, digital transformation with automation can not only save time and money, but also reduce risks and improve the compliance of faculty and students. Digital transformation means more time for everyone; reducing duplication of tasks that can be expensive and cumbersome. Today, many organizations are achieving efficiency through sharing, consolidation, or virtualization. In addition, digital transformation enables faculties and students to practice in a "safe space" where they can experiment, fail and retry, etc. and thus can help students practice, develop and gain confidence in their interpersonal skills. Digital Transformation supports the 3D simulated environment which is also valuable for developing professional skills as well as soft skills and enhancing the learner's experience (Nguyen Duc Son, 2019). Digital transformation enables the institution to handle the complex problems of teaching and learning, student management, etc. A university can "reach everyone at home where they are" not just in the classroom but wherever needed. Another experience might be a digitally and physically integrated 3D one. Today, the important point of teaching and learning experiences in schools is not only the physical environment but also the digital environment. Through digital transformation, the centralized use of data and artificial intelligent environments can satisfy students' needs with more relevant experiences.

In art pedagogical training, digital transformation play an important role in rapidly transforming the way people interact with each others, for example: between faculty and students; lecturers and lecturers...In particular, the digitization process creates a duplicate of the real environment (real world digitization). Everything is digitalized: from the smallest visual elements such as dots, lines, arrays, colors, textures, materials, etc. to the intricate visuals of finished designs. Moreover, the digitization process with automation support technology helps art pedagogical lecturers and students to "work" and create works tirelessly. The application softwares in art and design are diversified, abundant with plentiful functions to help learners overcome obstacles in skills and techniques in the drawing and design process. 
In Vietnam today, the universities specialised in Art training have invested in facilities to prepare for their digital transformation. However, the application of digital technology to teaching method innovation through computer systems and software application in the creation, design and art practice of learners has not yet been implemented and synchronized. The digitalization process has not yet been deployed towards digital transformation in each subject and towards the virtualization of the art teaching and learning environment.

\subsubsection{Impacts of digital transformation on training institutions}

- Regarding education in general:

First is connectivity. Lecturers and students are connected through teaching and learning activities in order to develop skills; they are also connected with work-related stakeholders. Poor connection between any factors would undermine the entire system. Through digital transformation, training institutions use "big data", combining realtime social demand information. Through analysis, it is possible to identify the skills that employers are in need. Data on supply and demand situation helps training institutions to design and adjust training programs, curriculum and add extracurricular and thematic activities to supplement knowledge and capacity of graduates. The essence of "university" teaching is connection, in which personal interaction between lecturers and students plays a decisive role in deciding the quality of training (SEAMEO, 2010), especially for a distinctive industry such as art pedagogy. Training institutions always provide the best conditions to foster the connections between the elements of the teaching process, disciplines, and community. In the field of arts pedagogy, the characteristics of gift training, direct contact and interaction between lecturers and students play an important role in inspiring innovation and creativity (Loveless, 2006). Digital transformation gives students and faculties more space and time to interact. The interaction with stakeholders in the teaching and learning process is also expanded and maximized.

Secondly, Digital Transformation promotes training institutions' activeness and creativeness. The digital transformation process helps universities expand and develop traditional teaching concepts, meanwhile create innovative and differentiated activities. The main concept is to virtualize all activities of teaching and learning based on digital technology as well as digitalize every element of teaching and learning to manifest the philosophy of training creatively and effectively. In the current context, changes must always happen quickly, to keep pace with the general development of society. Therefore, digital conversion is an option that cannot be ignored.

Third, digital technology is changing the day-to-day combination of activities. Some operations are effectively performed by machines to free up human time for other things. Teaching directly in the classroom is now not the only way to deploy learning. Teaching is not simply informational; but more about the provision of distance learning. That "approach" must be done effectively to promote the experience that is academically, socially, and emotionally engaging.

- Regarding art pedagogy:

First, with digital transformation, technology offers students a new way to create art together with new materials and means to practice art. Students can create their own works of art as well as apply traditional art to design and be creative through specialized application software at art studios or computer labs. In addition, digital conversion offers many applications that allow traditional art transformation (Hawks, 2010). Students can transform the art they have created with a variety of applications. Alternatively, students can use two or more apps to transform their artwork, for instance, taking pictures of drawings and editing and rendering them as new works of art.

Secondly, technology optimises the learning efficiency. Instead of repeating the teaching contents constantly, teachers can now use video playback in class. The essence of art is exclusive and there are some brush strokes that can only be drawn once and only once. Lecturers will not need to re-demo many times during the practice because if students are late or absent, they can watch the video of the technology-generated demonstration lectures. Many fine arts teachers have started to use this video playback learning model to reduce the time for presenting concepts, manipulations, etc. Moreover, Technology can transform the teaching strategies. Resources such as projectors, cameras, etc. can be adjusted for maximum efficiency. Technology allows lecturers to transform education and present information in new and efficient ways. There are even websites available to take students on field trips or virtual tours to famous museums around the world.

Third, technology effectively supports students' research and experimentation. They can participate in class research projects to study the arts and share ways of using technology in the classroom to engage people in the arts career. With technology, lecturers can easily track the progress of students' learning and research as well as manage students during specialized study hours. The digital catalog is used extensively in art classrooms. These are effective 
ways to see what artist students are doing and how their work is planned to help them "soar" in the creative world in a testable and controllable trajectory. In addition, Technology makes art learning more enjoyable. The goal of fine arts teaching is to find ways to make learning more enjoyable (Faber, 2009). Technology helps students learn new ways to share information, foster collaboration, develop critical thinking, communication, creativity, in a very interesting way.

Fourth, technology provides many solutions to assess the ability of art pedagogical students objectively. Evaluating artworks with the help of technology can help ease teachers' sentimentality by creating easy, effective methods of assessment (McFarlane, 2001). In addition, technology also assists lecturers in checking the copyright of students' works on cyberspace (The Internet), which helps to prevent piracy and plagiarism.

Fifth, technology also offers students the opportunity to practice working well with others, fostering collaborative learning and engagement in art projects. The faculty's main concern in the classroom is student participation; therefore, learning activities must be engaging. Technology is a great way to engage students in and interested in discussion topics. Whether it is watching a slide presentation of famous artworks or artwork analytical review, it must be engaging to easily capture students' attention. Digital technology enables interactive learning that promotes student engagement.

\subsubsection{Solutions to improve the quality of art pedagogy training in Vietnam today}

Through the analysis of digital technologies in the field of pedagogy in general and art pedagogy, we have pinpointed some common factors in most art pedagogical training institutions in Vietnam today. Therefore, based on the specific elements of art pedagogy, we propose a digital transformation model to shape and develop digital transformation strategies. The model provides some solutions that should be applied with minor adjustments to match each training institution in their actual situation.

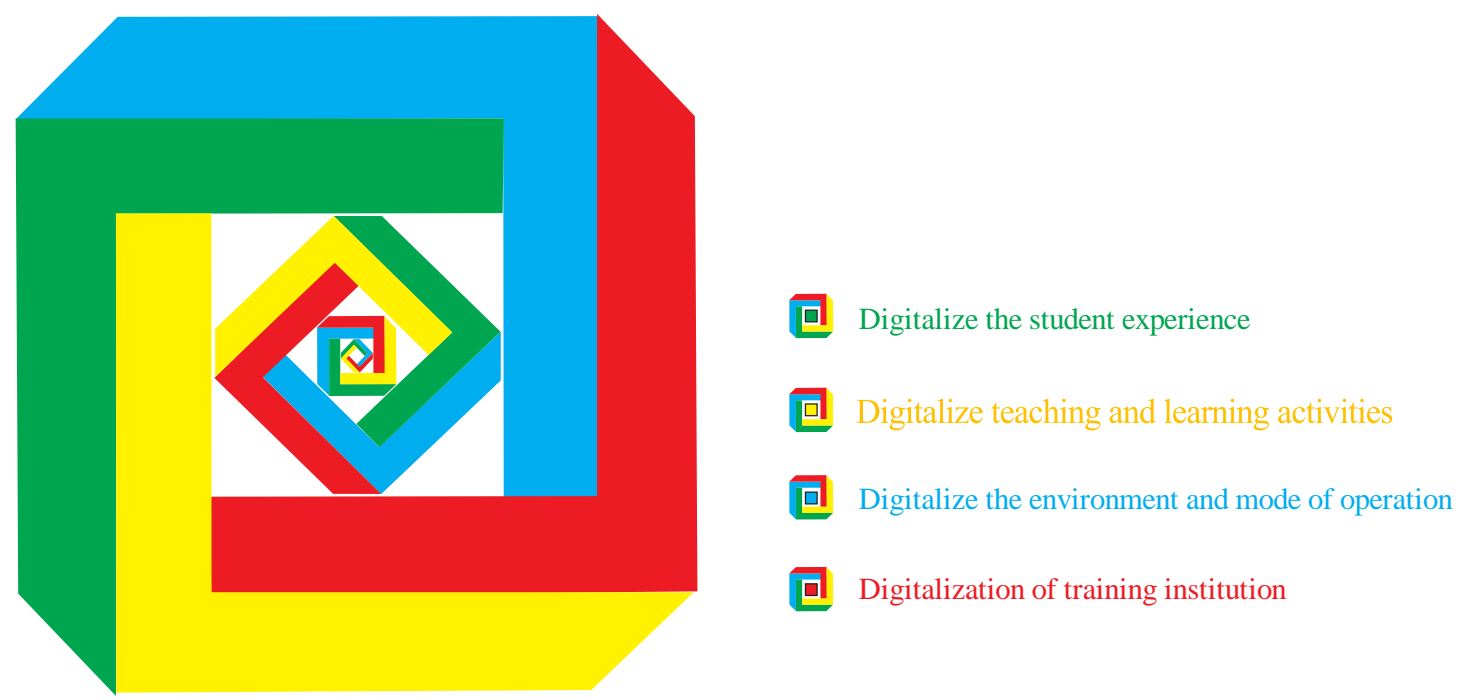

Image 1. Digital transformation Model in art pedagogy training

\subsubsection{Digitalizing student experience}

Today, instead of focusing on imparting only disciplinary knowledge, universities need to enhance learners' experience, especially with the specialized subjects. There are more and more teaching and learning activities that both generate data and connected to each other through the Internet. It seems a matter of fact that most art pedagogical training institutions in Vietnam neglects the inclusion of necessary knowledge and skills to exploit the Internet as a tool for learning and creativity. Their art pedagogical training programs exclude the subject of Internet exploitation and application in online art creation and design. Consequently, students access these art forums spontaneously without professional orientation, which may cause confusion among students when composing art, or worse, a distorted view of art. However, without the online art forums and communities of digital artists, it would be difficult for students to access and develop artistic knowledge. It is the Internet that has led them to the work of countless famous artists from all over the world in all fields of visual arts. It can be said that many art students participate in online exchanges and evolve from the Internet environment. The feedback from other artists is extremely helpful, 
and through the reviews it teaches them extensively from minor technical problems to broader issues. That is why connecting and taking advantages of the Internet's facilities to complement the school's training program and enhance learners' experience should be highlighted and promoted.

\subsubsection{Digitalizing teaching and learning activities}

To achieve this goal, training institutions need to research how they can interact with learners throughout their learning. Currently, the application of IT in University teaching method innovation follows two basic directions: + Increasing the application of positive pedagogical methods towards problem solving; + Apply teaching technology to make the most of new tools and technologies that the achievements of science and technology offer. Digitizing teaching and learning activities is the optimal solution to realize digital conversion. Classrooms should be equipped with large touch screens to facilitate students' engagement to lectures. Each student should have access to a computer with Internet connection to guarantee the availability of learning materials and evaluation comments from teachers. Universities libraries should allow students to access the library management system on computers and search for. Students should be able to experience virtual reality tours (Nguyen Duc Son, 2019). Integrating course management softwares helps teachers oversee the learning progress of students and students to share and discuss related documents, videos, audio lessons with lecturers or groups of peers. In addition, artificial intelligence (AI) applications can save time by improving information discovery and retrieval, as well as collecting and aggregating information from social media... The AI can chat with fellow students about their topics of interest. Thereby, machines with artificial intelligence can take over some responsibilities and free up faculty and students.

\subsubsection{Digitalizing the environment and mode of operation}

Advanced digital technology powered by sensors, can improve the teaching and learning process in several ways. Big data analytics, for example, can maintain the smooth process of teaching and learning by tracking, analyzing and reporting activities that are happening; cloud can be used to create unified teaching processing platforms; and mobile platforms that allow teaching and learning to be done anytime, anywhere and on any device. Through automation, standardization, and training processes, training institutions can respond more quickly to changing practices and social needs. As a result, they are able to improve the quality of training. Such agility is essential because competitiveness increasingly depends on responding to and anticipating fast or changing trends. Indeed, the underlying principle of the teaching theory 'World University' highlights: Intensification (Enhancing teaching efficiency and learning activeness); Individualization; Industrialization (Teaching chemistry). Digital transformation needs to diversify teaching methods as technology develops: + E-learning helps teachers and students interact more. The boundaries of traditional learning models are almost no longer dominant when the technology of management and learning aids has moved beyond the school framework and created new learning habits; + Learning method using virtual reality gives learners an experience like learning in a real classroom. With the application of virtual reality, an education without distance will be shaped.

\subsubsection{Digitalization of training institution/ university}

Digital solutions can support training institutions to work more closely with each other. Organizations can shape and participate in the ecosystem on their own, while training many students, and diversifying the variety of educational services that add value to the learners' experience. Digitalizing organizations through the establishment of: School management system (assisting the school in managing administrative affairs and completing general policies and regulations); Learning management system (classroom management on digital platforms, helping teachers connect with students and stakeholders, managing learning progress and sharing lecture content...); Student management system. The digitization of the organization can fundamentally change the organizational structure in the direction of streamlining, saving human and material resources, optimizing the operation of the training institution... However, digital transformation requires digital media processing methods in teaching and learning, teaching pedagogical communication skills in training and education, and using artificial intelligence to drive learning.

Universities can start digital transformation strategies from the smallest steps, not necessarily investing in largescaled technology transformation projects, such as digitizing documents to limit paper printing, digitizing workflows, controlling jobs with a cloud-based solutions... On that basis, they can think about innovation and digital culture within the organization will take shape, then the institution can continue to deploy larger applications for sustainable development. 


\section{DISCUSSION AND CONCLUSION}

In short, in a rapidly changing world in the era of IT development and digital transformation, Vietnam education in general and art pedagogy have golden opportunities to thrive. Digital transformation by promoting IT applications aims to foster innovation in content, teaching and learning methods, and assessment in all subjects. The important thing is to implement synchronous solutions: digitizing the student experience; digitizing teaching and learning activities; digitizing the environment and mode of operation; digitizing training facility. Developing centralized data, e-learning models, e-lesson design softwares, virtual reality simulated softwares and AI software undertaking more teaching and learning tasks help to unfetter lecturers and students. Digital transformation needs to diversify teaching methods as technology develops as e-learning supports teachers and students to interact more. The boundaries of traditional learning models have been gone beyond the school framework and created new learning habits. With the application of virtual reality, an education without distance will be formed. Digital transformation requires innovative thinking to shape digital culture in university, and eventually the sustainable development. Today, whether training institutions are using ample technologies or have just started to approach the implementation of technology in pedagogical training in general and art pedagogy in particular, they are taking steps in the right direction. It is time for universities to transform digitally and strategically to develop and solve the practical problems effectively.

\section{REFERENCES}

Bilyalova, A., Salimova, D., Zelenina, T. (2020). Digital Transformation in Education. In: Antipova T. (eds) Integrated Science in Digital Age. ICIS 2019. Lecture Notes in Networks and Systems, 78. Springer, Cham. https://doi.org/10.1007/978-3-030-22493-6_24

Faber, H. (2009). Digital Drawing Tablet to Traditional Drawing on Paper. Iowa State University, College of Design.

Hawks, P. (2010). The relevance of traditional drawing in the digital age. Thames Valley University.

Loveless, M. (2006). Literature Review in Creativity, New Technologies and Learning. School of Education, University of Brighton.

Marshall McLuhan \& Bruce R. Powers. (1989). The Global Village: Transformations in World Life and Media in the $21^{\text {st }}$ Century. Oxford University Press, USA. ISBN-13 978-0-19 507910-4.

McFarlane, A. (2001). Perspectives on the relationships between ICT and assessment. Journal of Computer Assisted Learning, 17, 227-234.

Ngoc Linh (2020). Online education in Vietnam - The potential market. https://doimoisangtao.vn/news/gio-dc-trctuyn-vit-nam

Nguyen Duc Son (2019). 3D VR web design application to enhance user experience. International workshop on artistic composition and design, ISBN 978604685469 2, pp. 132-138.

Politburo (2019). Resolution No. 52-NQ / TW dated September 27, 2019 on a number of guidelines and policies to actively participate in the Fourth Industrial Revolution.

Prime Minister (2020). Decision No. 749/QD-TTg dated June 3, 2020 approving the National Digital Transformation Program to 2025, with a vision to 2030.

Scherling, Laura S. (2020). Learning During a Digital Transformation in Communication Design: Faculty, Professional, and Student Views on Changing Pedagogical Practices. Columbia University Libraries.

SEAMEO (2010). Status of ICT Integration in Education in Southeast Asian Countries. Bangkok: The Southeast Asian Ministers of Education Organization (SEAMEO).

Suárez-Guerrero, C., Lloret-Catalá, C., Mengual-Andrés, S. (2016). Teachers' Perceptions of the Digital Transformation of the Classroom through the Use of Tablets: A Study in Spain. Media Education Research Journal, 24(2). DOI: 10.3916/C49-2016-08 